\title{
Neoplasm of Uncertain Malignant Potential
}

National Cancer Institute

\section{Source}

National Cancer Institute. Neoplasm of Uncertain Malignant Potential. NCI Thesaurus. Code C3646.

A neoplasm displaying morphologic, phenotypic, or genotypic characteristics that are clearly not benign but do not permit the establishment of a definitive diagnosis of malignancy. Such neoplasms may or may not eventually have a more aggressive clinical course. Representative examples include lymphoproliferations of uncertain malignant potential (e.g., lymphomatoid granulomatosis and lymphomatoid papulosis), borderline ovarian epithelial neoplasms (e.g., borderline ovarian endometrioid tumor and borderline ovarian mucinous tumor), borderline exocrine pancreatic neoplasm (e.g., pancreatic borderline intraductal papillary-mucinous neoplasm), and primary borderline peritoneal epithelial neoplasm. 